YULEI LUO

WILLIAM T. SMITH

HENG-FU ZOU

\title{
The Spirit of Capitalism, Precautionary Savings, and Consumption
}

\begin{abstract}
Recent research has shown that the "spirit of capitalism"- a preference for wealth itself, in addition to consumption-has important implications for growth and asset pricing. This paper explores how the spirit of capitalism affects saving and consumption behavior. We demonstrate that the spirit of capitalism may reduce the importance of precautionary savings. It can also explain the excess sensitivity puzzle: the spirit of capitalism causes dramatic deviations from a random walk. It may also offer a partial explanation of the excess smoothness puzzle.
\end{abstract}

JEL codes: C61, D91, E21

Keywords: the spirit of capitalism, consumption and saving behavior, the sensitivity and smoothness of consumption.

The GREAT SOCIOLOGIST Weber (1948) viewed the desire to accumulate wealth as an end in itself as the defining characteristic of capitalist societies. Recently, this notion of the "spirit of capitalism" has been used to address a range of issues, including savings (Zou 1995, Carroll 2000), growth (Zou 1994, Smith 1999, Gong and Zou 2001, 2002), asset pricing (Bakshi and Chen 1996, Smith 2001), and the distribution of wealth (Luo and Young Forthcoming). In this paper, we extend the inquiry to explore how the spirit of capitalism affects precautionary savings and the dynamics of consumption.

We are very grateful to Pok-sang Lam and two anonymous referees for their helpful comments.

Yuler Luo is Assistant Professor at the School of Economics and Finance, University of Hong Kong (E-mail: yluo@econ.hku.hk). William T. Sмітн is Professor in the Department of Economics at Fogelman College of Business and Economics, University of Memphis (E-mail: wtsmith@memphis.edu). Heng-Fu Zou is Senior Economist at The World Bank, and Professor of CEMA at the Central University of Finance and Economics, Shenzhen University, and IAS at Wuhan University (E-mail: hzou@worldbank.org).

Received November 8, 2006; and accepted in revised form January 30, 2008.

Journal of Money, Credit and Banking, Vol. 41, No. 2-3 (March-April 2009)

(C) 2009 The Ohio State University 
Section 1 of the paper develops a very general model of precautionary savings in the presence of the capitalist spirit. As in most models of precautionary savings, we consider a consumer who knows his current wage but is uncertain about his future wage income (see the excellent survey by Carroll 2001). Following Zou (1994) we model the spirit of capitalism by allowing the consumer to derive utility from wealth itself, in addition to consumption. We use a very general utility function and assume only that income is a discrete-time diffusion process. Using the methods of Grossman and Shiller (1982), we derive an exact expression for the expected growth of consumption in the continuous-time limit. This is of some interest in itself, since most of the literature on consumption relies upon approximations (Baxter and Jermann 1999, Lettau and Ludvigson 2001, Gourinchas and Parker 2002), or restrictive assumptions about preferences (constant absolute risk aversion [CARA] as in Blanchard and Mankiw 1988, Hall 1988, Caballero 1990), or the income process (e.g., log-normality in Hansen and Singleton 1983, Carroll 1992). We demonstrate that the spirit of capitalism causes the random walk hypothesis (Hall 1978, 1988) to fail: (nonstochastic) changes in wealth can be used to predict changes in consumption if there is a spirit of capitalism.

To shed more light on how the spirit of capitalism affects savings and consumption, Section 2 develops a simple model that allows a closed-form solution: consumers have CARA preferences over consumption and wealth, and income is an $\mathrm{AR}(1)$ process. This model has interesting implications for both precautionary savings and consumption dynamics. First, the capitalist spirit usually (unless income is stationary and converges to its ergodic distribution very rapidly) reduces the precautionary savings premium.

Second, the spirit of capitalism can explain the excess sensitivity of consumption to anticipated changes in income (Flavin 1981, Campbell and Mankiw 1989, Deaton 1992): when there is a spirit of capitalism, the growth of consumption can be predicted by expected changes in income. This is consistent with the empirical results of Campbell and Mankiw (1989), who regress consumption growth on income growth. The coefficient attached to income growth in their regression is large and statistically significant. They interpret this coefficient as the proportion of "rule-of-thumb" consumers in the economy. Our model suggests that this coefficient can also be interpreted as a measure of the strength of the spirit of capitalism.

Third, the spirit of capitalism may offer a partial explanation of the excess sensitivity of consumption growth to unanticipated changes in income. Friedman's famous permanent income hypothesis suggests that consumption should be smoother than income. However, Campbell and Deaton (1989) and Deaton (1992) argue convincingly that income is nonstationary. In this case, the permanent income hypothesis predicts that innovations to income should be associated with larger innovations in consumption. This is the excess smoothness paradox: if income is nonstationary, observed consumption growth is much too smooth, relative to the consumption path predicted by the permanent income hypothesis. In our model, the spirit of capitalism mitigates the effect of an income innovation on consumption growth as long as income is nonstationary. 
Section 3 offers some concluding thoughts.

\section{THE MODEL}

Suppose that time is divided into discrete intervals of length $\Delta t$ (we will be considering the limit as $\Delta t \rightarrow 0$ ). Imagine a representative consumer with an infinite planning horizon and a constant rate of time preference $\theta>0$. He maximizes the lifetime expected utility of time-separable preferences defined over consumption $c_{t}$ and wealth $w_{t}$ :

$$
E_{0} \sum_{t=0}^{\infty}\left(\frac{1}{1+\theta \Delta t}\right)^{t / \Delta t} U\left(c_{t}, w_{t}\right) \Delta t,
$$

where the summation is over $\Delta t, 2 \Delta t$, etc. We assume that $U\left(c_{t}, w_{t}\right)$ is twice continuously differentiable in $c_{t}$ and $w_{t}$, and that $U_{c}>0, U_{w}>0, U_{c c}<0$, and $U_{w w}<0$.

The consumer can borrow and lend at the riskless rate of return $r$, and receives income (or more generally, nonasset income) of $y_{t}$ in each period. His budget constraint is therefore

$$
w_{t+\Delta t}=w_{t}(1+r \Delta t)+y_{t} \Delta t-c \Delta t .
$$

In keeping with most of the literature on precautionary savings (Carroll 2001), we assume that the consumer knows his income in each period but is uncertain about its future evolution. That is, there is "future" uncertainty, but not "current" uncertainty. We employ a very general income process, assuming only that it is a discrete-time diffusion

$$
\Delta y_{t}=y_{t+\Delta t}-y_{t}=\mu_{y, t} \Delta t+\Delta z_{t},
$$

where $\Delta z_{t}=\sigma_{y, t} B_{y, t} \sqrt{\Delta t}$ and $t$ is standard normal. The conditional expectation and standard deviation of the growth of income, $\mu_{y, t}$ and $\sigma_{y, t}$, may be time varying.

The consumer maximizes the expected lifetime utility in equation (1), subject to the budget constraint in equation (2), given initial wealth $w_{0}$ and the income process in equation (3). The Euler equation for this problem is

$$
U_{c}\left(c_{t}, w_{t}\right)=\frac{1}{1+\theta \Delta t} E_{t}\left[(1+r \Delta t) U_{c}\left(c_{t+\Delta t}, w_{t+\Delta t}\right)+U_{w}\left(c_{t+\Delta t}, w_{t+\Delta t}\right)\right] .
$$

Using the limiting arguments of Grossman and Shiller (1982) (and more recently employed by Bakshi and Chen 1996, Smith 2001), we can use this first-order condition to infer the stochastic process for the optimal consumption path. Define $\sigma_{c, t}^{2}$ as the (possibly time-varying) instantaneous variance of the growth of consumption, we prove: 
Proposition 1. In the continuous-time limit, as $\Delta t \rightarrow 0$, the expected growth of consumption is

$$
\begin{aligned}
E_{t} d c_{t}= & -\frac{U_{c}\left(c_{t}, w_{t}\right)}{U_{c c}\left(c_{t}, w_{t}\right)}(\theta-r) d t-\frac{U_{w}\left(c_{t}, w_{t}\right)}{U_{c c}\left(c_{t}, w_{t}\right)} d t-\frac{U_{c w}\left(c_{t}, w_{t}\right)}{U_{c c}\left(c_{t}, w_{t}\right)} d w_{t} \\
& -\frac{U_{c c c}\left(c_{t}, w_{t}\right)}{U_{c c}\left(c_{t}, w_{t}\right)} \frac{\sigma_{c, t}^{2}}{2} d t .
\end{aligned}
$$

Proof. First, assume that the optimal consumption policy is a discrete-time diffusion

$$
\Delta c_{t}=c_{t+\Delta t}-c_{t}=\mu_{c, t} \Delta t+\sigma_{c, t} \Delta z_{c, t} .
$$

For convenience, express the (instantaneously nonstochastic) growth in wealth using analogous notation

$$
\Delta w_{t}=\mu_{w, t} \Delta t
$$

Now consider the Euler equation in equation (4). Take a second-order Taylor series of the right-hand side around $\Delta t=0, c_{t+\Delta t}=c_{t}$, and $w_{t+\Delta t}=w_{t}$. Using equations (6) and (7), this leads to

$$
\begin{aligned}
0= & \left(U_{c}\left(c_{t}, w_{t}\right)(r-\theta)+U_{w}\left(c_{t}, w_{t}\right)\right) \Delta t+U_{c c}\left(c_{t}, w_{t}\right) \mu_{c, t} \Delta t \\
& +U_{c w}\left(c_{t}, w_{t}\right) \mu_{w, t} \Delta t+U_{c c c}\left(c_{t}, w_{t}\right) \frac{E_{t} \Delta c_{t}^{2}}{2}
\end{aligned}
$$

Using equation (6) and the Ito multiplication rule, we have $E_{t} \Delta c_{t}^{2}=\sigma_{c, t}^{2} \Delta t$. Taking the limit of equation (8) as $\Delta t \rightarrow 0$ and rewriting the resulting equation yields equation (5).

Equation (5) warrants closer inspection. Two of the terms in equation (5) will look familiar; the other two are new.

Consider the familiar terms first. The first term in equation (5) is similar to the continuous-time Euler equation in nonstochastic models without the spirit of capitalism: the consumption profile in nonstochastic models depends upon the difference between the interest rate and the rate of time preference. The last term in equation (5) is a precautionary savings premium (Carroll 1992) that changes the slope of the consumption profile. The new terms in equation (5) are the second and third. The second asserts that the spirit of capitalism $\left(U_{w}>0\right)$ by itself tends to steepen the consumption profile.

More importantly, the third term shows that if there is a spirit of capitalism then the expected growth of consumption generally (as long as $U_{c w} \neq 0$ or $U_{w w} \neq 0$ ) depends upon the (instantaneously nonstochastic) growth in wealth. In other words, growth in wealth can be used to predict growth in consumption. Thus, the spirit of capitalism causes the random walk hypothesis to fail. 
It is also important to note that expressions like equation (5) are common (e.g., Carroll 1992, Campbell 1994, Baxter and Jermann 1999, Lettau and Ludvigson 2001) as log-linear approximations. Log-linear Euler equations are very popular in solving stochastic general equilibrium models in macroeconomics. Other papers arrive at closed-form solutions, but impose restrictive assumptions about either preferences or the income process. Here, however, this relationship holds exactly in the continuous-time limit, for a very general income process and a very general class of preferences.

\section{CARA PREFERENCES}

In order to shed more light on how the spirit of capitalism affects the precautionary premium and dynamics of consumption, it will be useful to consider an example that permits a closed-form solution. To this end, suppose that time is continuous and that the expected lifetime utility is of the following form: ${ }^{1}$

$$
-\frac{1}{\alpha} E_{0} \int_{0}^{\infty} e^{-\theta t-\alpha c_{t}-\lambda w_{t}} d t
$$

The parameter $\alpha$ is the coefficient of absolute risk aversion with respect to consumption. The parameter $\lambda \geq 0$ measures the strength of the spirit of capitalism. If $\lambda=0$, there is no spirit of capitalism and we recover the familiar case of CARA defined over consumption alone.

In continuous-time, the consumer's budget constraint is

$$
d w_{t}=\left(r w_{t}+y_{t}-c_{t}\right) d t
$$

Income is a continuous-time, first-order autoregressive (Ornstein-Uhlenbeck) process

$$
d y_{t}=\rho\left(\frac{\mu}{\rho}-y_{t}\right) d t+\sigma d z_{t} .
$$

The steady-state mean of income is $\bar{y}=\mu / \rho$. The parameter $\rho$ governs the speed of convergence (or divergence) from the steady state. If $\rho>0$, the process is stationary; deviations of income from the steady state are temporary. If $\rho<0$, the process is

1. Although we adopt the representative agent framework, the model in principle could be generalized to allow for consumer heterogeneity. Suppose there is a continuum of consumers. Each consumer's income consists of an idiosyncratic component and an aggregate component. After solving for the optimal consumption rules of individual consumers, we aggregate across all consumers and obtain an expression for aggregate consumption. Since idiosyncratic income components would be canceled out after aggregation, however, aggregate consumption would only depend upon aggregate income. We conjecture that the "aggregate" model with heterogeneity would therefore have the same implications for aggregate consumption and precautionary savings as would the representative agent model. 
nonstationary and innovations to income are "superpermanent." This last case catches the flavor of Campbell and Deaton's (1989) argument that income is nonstationary. ${ }^{2}$

The consumer chooses a consumption policy to maximize expected lifetime utility in equation (9), subject to the budget constraint in equation (10), and given the income process in equation (11). If $\lambda=\rho=0$, this reduces to the canonical precautionary savings problem with random-walk income in Hall (1988). If $\lambda=0$ but $\rho>0$, it becomes a continuous-time version of the precautionary savings problem with autoregressive income of Caballero (1990).

In an appendix (available on request) we use the methods of Merton (1971) and Wang (2006) to demonstrate that the solution to this problem is the consumption function

$$
c\left(w_{t}, y_{t}\right)=\Omega\left(w_{t}, y_{t}\right)-\Gamma \frac{\sigma^{2}}{2}
$$

where

$$
\Omega\left(w_{t}, y_{t}\right)=\frac{\theta-r-\lambda / \alpha}{\alpha r+\lambda}+\frac{1}{r+\lambda / \alpha+\rho} \mu+\frac{r+\lambda / \alpha}{r+\lambda / \alpha+\rho} y_{t}+r w_{t},
$$

and

$$
\Gamma=\alpha \frac{r+\lambda / \alpha}{(r+\lambda / \alpha+\rho)^{2}} .
$$

In the appendix available upon request, we also show that the consumer's transversality condition is $\lim _{t \rightarrow \infty} E e^{-\theta t}\left|J\left(w_{t}, y_{t}\right)\right|=0$, where $J\left(w_{t}, y_{t}\right)$ is the consumer's value function when his financial wealth is $w_{t}$ and his wage income is $y_{t}$. A sufficient and necessary condition for this to be satisfied is that the effective rate of interest be positive, $r+\lambda / \alpha>0$.

This solution shares features common to all CARA models of precautionary savings (see Hall 1988, Caballero 1990 for just two examples). First, consumption decomposes into two parts, certainty-equivalent consumption $\Omega\left(w_{t} y_{t}\right)$ and a risk premium $-\Gamma \sigma^{2} / 2 .^{3}$ Second, certainty-equivalent consumption is a linear function of financial wealth $w_{t}$ and wage income $y_{t}$.

Notice that this solution is identical to the consumption function without the spirit of capitalism but with an interest rate of $r+\lambda / \alpha$ rather than $r$ In other words, the spirit of capitalism has the effect of raising the interest rate. The intuitive explanation for this is straightforward. Suppose that I save a dollar of my wage income. In the absence of the spirit of capitalism this will yield $1+r$ dollars one period hence, so the appropriate rate with which to discount my wage income is just the interest

2. Campbell and Deaton (1989) argue that income is a nonstationary second-order process. It is not possible to derive a closed-form solution to the precautionary savings problem with a second-order process, so we have focused on the first-order process in equation (3). This is tractable yet allows a form of nonstationarity.

3. It is "certainty equivalent" in the sense that it is the consumption predicted by a nonstochastic model with CARA utility. "Certainty equivalent" is often used to describe linear-quadratic preferences, which do not generate a precautionary savings premium. 
rate. In the presence of the spirit of capitalism, however, investing the same dollar yields psychic returns because the increase in wealth raises utility. In other words, the market rate $r$ is augmented by the "psychic" rate of return $\lambda / \alpha$ (the relative strength of the preference for wealth versus consumption). Therefore, $r+\lambda / \alpha$ is the effective "psychological" rate at which the consumer discounts wage income.

It is also illuminating to express the consumption function in terms of human wealth. Following the literature, we can define human capital as the expected present value of future labor income discounted at the appropriate interest rate. In the presence of the spirit of capitalism the effective rate of interest is $r+\lambda / \alpha$. Therefore, human wealth is

$$
h_{t}=E_{t} \int_{t}^{\infty} e^{-(r+\lambda / \alpha)(s-t)} y_{s} d s
$$

Straightforward calculations imply that

$$
h_{t}=\frac{1}{r+\lambda / \alpha+\rho}\left(y_{t}+\frac{\mu}{r+\lambda / \alpha}\right) \text {. }
$$

If $r+\lambda / \alpha+\rho<0$, the integral in equation (15) diverges, so that human wealth is undefined. Henceforth we therefore assume that $r+\lambda / \alpha+\rho>0$. In other words, income cannot be "too" nonstationary.

Using equation (16), the consumption function in equations (12)-(14) can then be rewritten as

$$
c\left(w_{t}, y_{t}\right)=\frac{1}{\alpha} \frac{\theta-r-\lambda / \alpha}{r+\lambda / \alpha}+(r+\lambda / \alpha) h_{t}+r w_{t}-\Gamma \frac{\sigma^{2}}{2},
$$

which means that consumption is linear in financial wealth and human wealth.

We will now explore how the spirit of capitalism (captured by the parameter " $\lambda$ ") affects the precautionary premium and the time-series properties of consumption.

\subsection{The Precautionary Savings Premium}

Consider first the precautionary savings premium. In the absence of the capitalist spirit $(\lambda=0)$, the precautionary savings premium is simply

$$
P_{\lambda=0}=\frac{r}{(r+\rho)^{2}} \alpha \frac{\sigma^{2}}{2} .
$$

Note for future reference that $\partial P_{\lambda=0} / \partial r<=>0$ as $r>=<0$. That is, an increase in the interest rate will decrease or increase the premium depending upon whether $r>\rho$ is positive or negative. Nonstationary income $(\rho<0)$ is a sufficient condition for an increase in the interest rate to reduce the precautionary premium. 
Things are quite different if there is a capitalist spirit $(\lambda>0)$. In this case, the premium is

$$
P_{\lambda>0}=\alpha \frac{r+\lambda / \alpha}{(r+\lambda / \alpha+\rho)^{2}} \frac{\sigma^{2}}{2} .
$$

Recall that the "effective" interest rate in the presence of the spirit of capitalism is $r+\lambda / \alpha$ rather than $r$. It follows that the spirit of capitalism may decrease or increase the precautionary premium depending upon whether the effective rate of interest exceeds the rate of time preference. That is, $\partial P_{\lambda>0} / \partial \lambda<=>0$ as $r+\lambda / \alpha>=<\rho$.

We distinguish between two cases. On the one hand, if income is nonstationary $(\rho<0)$, then the premium always decreases with the spirit of capitalism. On the other hand, if income is stationary $(\rho>0)$, then the effect of the spirit of capitalism on the premium is nonmonotonic. ${ }^{4}$ If $r+\lambda / \alpha \geq \rho$, then the premium still decreases with the strength of the spirit of capitalism. However, if income is stationary and $r+\lambda / \alpha<\rho$, then the premium will actually decrease with the spirit of capitalism. We now have the following proposition.

PROPOSITION 2. An increase in the spirit of capitalism always lowers the precautionary premium if income is nonstationary. If income is stationary, then the precautionary premium initially increases with the spirit of capitalism, and then falls.

\subsection{Excess Sensitivity and Excess Smoothness}

The spirit of capitalism has important implications for the two fundamental puzzles of consumption dynamics, excess sensitivity and excess smoothness. To see why, consider first the case where there is no spirit of capitalism. Using equations (12)(14) and setting $\lambda=0$, the growth of consumption is simply

$$
d c_{t}=r\left[\frac{r-\theta}{\alpha r}+\alpha \frac{r}{(r+\rho)^{2}} \frac{\sigma^{2}}{2}\right] d t+\frac{r}{r+\rho} \sigma d z_{t} .
$$

Note two properties of consumption growth in this benchmark case. First, it reflects Hall's $(1978,1988)$ classic result that consumption should be a random walk under rational expectations. As shown by Caballero (1990), Hall's conclusion is not affected by the persistence of income: current and lagged consumption and income cannot help predict the growth of consumption. In fact, it has been documented again and again (e.g., Flavin 1981, Campbell and Mankiw 1989, Deaton 1992) that changes in income predict changes in consumption. This is the excess sensitivity puzzle.

Second, the innovation to consumption is equal the annuity value of the innovation to income (also a result due to Caballero 1990). This implies that if income is stationary $(\rho>0)$ the variance of consumption growth is less than the variance of income growth,

4. $P_{\lambda>0}$ reaches a maximum at $\lambda^{*}=\alpha(\rho-r)$. If $\rho<0$, then $\lambda^{*}<0$ so that $P_{\lambda>0}$ falls monotonically with $\lambda$ for $\lambda \geq 0$. However, if $\rho>0$, then $\lambda^{*}>0$; in this case, $P_{\lambda>0}$ rises to a maximum and then falls as $\lambda$ increases for $\lambda \geq 0$. 
as one would expect from the consumption smoothing suggested by the permanent income hypothesis. If income is nonstationary $(\rho<0)$, however, the variance of consumption growth exceeds the variance of income growth. This leads to the excess smoothness puzzle, or Deaton (1992) paradox: if income is nonstationary, observed consumption growth is actually too smooth relative to what the permanent income hypothesis predicts.

How does the spirit of capitalism $(\lambda>0)$ alter these predictions? The expected growth of consumption is now

$$
E_{t} d c_{t}=r\left[\frac{r+\lambda / \alpha-\theta}{\alpha r}+\alpha \frac{r+\lambda / \alpha}{(r+\lambda / \alpha+\rho)^{2}} \frac{\sigma^{2}}{2}\right]-\frac{\lambda}{\alpha} d w_{t} .
$$

If there is a capitalist spirit, so that $\lambda>0$, the expected change in consumption can be predicted by the growth in wealth. This is a special case of Proposition 1, equation (5) in the general model in Section 1.

To develop further insights about how the spirit of capitalism affects consumption dynamics, it is useful to use the budget constraint in equation (10) to rewrite consumption growth as

$$
\begin{aligned}
d c_{t}= & r\left[\frac{1}{\alpha} \frac{r-\theta+\lambda / \alpha}{r+\lambda / \alpha}+\Gamma \frac{\sigma^{2}}{2}\right] d t+\frac{\lambda / \alpha}{r+\lambda / \alpha+\rho} E_{t} d y_{t} \\
& +\frac{r+\lambda / \alpha}{r+\lambda / \alpha+\rho} \sigma d z_{t} .
\end{aligned}
$$

Consumption is no longer a random walk when there is a capitalist spirit: the anticipated growth of wage income can be used to predict changes in consumption when $\lambda>0$. Therefore, the spirit of capitalism provides an alternative explanation for the excess sensitivity of consumption to income.

This suggests an alternative interpretation of the empirical results of Campbell and Mankiw (1989). They regress consumption growth on income growth. The estimated coefficient attached to income growth in this regression is large and statistically significant. They interpret this number as the proportion of "rule-of-thumb" consumers in the economy. Our model implies that this coefficient can also be viewed as a measure of the strength of the spirit of capitalism.

Finally, consider the excess smoothness puzzle. In the absence of the spirit of capitalism, when $\lambda=0$, the growth of consumption is given by equation (20). Hence, the standard deviation of consumption growth is

$$
\operatorname{std}\left(d c_{t}\right)=\frac{r}{r+\rho} \sigma .
$$

From equation (22), however, the standard deviation of consumption growth in the presence of the spirit of capitalism is

$$
\operatorname{std}\left(d c_{t}\right)=\frac{r+\lambda / \alpha}{r+\lambda / \alpha+\rho} \sigma .
$$


To show how the spirit of capitalism affects excess smoothness, we define the excess smoothness ratio as

$$
\Lambda=\frac{\operatorname{std}\left(d c_{t}\right)}{\operatorname{std}\left(d y_{t}\right)}=\frac{r+\lambda / \alpha}{r+\lambda / \alpha+\rho} .
$$

Since absolute risk aversion $\lambda>0$, it follows immediately that $\Lambda><1$ as $\rho><0$. Indeed, $\partial \Lambda / \partial \lambda><0$ as $\rho><0$. This implies that the spirit of capitalism mitigates the volatility of consumption growth when income is nonstationary. In other words, the spirit of capitalism provides an alternative explanation for the excess smoothness puzzle, because it reduces the volatility of consumption growth when income is nonstationary.

We do not claim, however, that this simple model—with CARA utility and AR(1) income - can fully explain excess smoothness. It is obvious from equation (25) that if income is nonstationary, the excess smoothness ratio falls and tends to one $(\Lambda \rightarrow 1)$ as the spirit of capitalism gets large $(\lambda \rightarrow \infty)$. In other words, this basic model predicts the excess smoothness ratio will have a lower bound at one when income is nonstationary. However, in the U.S. aggregate data, the excess smoothness ratio is close to 0.58 . Hence, the spirit of capitalism itself cannot resolve the excess smoothness puzzle in this simple model. Nonetheless, the spirit of capitalism can help resolve this puzzle when embedded in richer and more realistic economic environments. Specifically, it is possible to show that if either (i) there are permanent and transitory components to income or (ii) there is interest rate risk, then the spirit of capitalism can generate a plausible excess smoothness ratio. We have established these results in a longer version of the paper, available upon request. Although these extensions make the model more realistic, they shed little additional light on how the spirit of capitalism affects excess smoothness.

\section{CONCLUSION}

Ever since Weber (1948), the spirit of capitalism has been recognized by sociologists as an essential aspect of modern, capitalist economies. It has only been over the last decade, however, that - as part of a broader effort to address problems of envy and "keeping up with the Joneses"-economists have formalized this notion. The modern economic literature on the spirit of capitalism has investigated its implications for growth and asset-pricing. Conspicuously absent from this literature has been how the spirit of capitalism affects consumption and savings behavior under uncertainty. In this paper, we fill this gap by incorporating the spirit of capitalism into a model of precautionary savings.

Our model with a simple AR(1) income process suggests that the capitalist spirit may increase or decrease the precautionary premium, depending upon the degree of nonstationarity of income. It also shows that the spirit of capitalism provides a simple explanation for excess smoothness: it generates dramatic deviations from the 
random walk hypothesis. By itself, the spirit of capitalism does not provide a plausible explanation for excess smoothness.

The model may have interesting cross-country implications. Zou (1995) argued that the high saving rates in East Asian countries and regions like Japan, Taiwan, South Korea, Singapore, and Hong Kong may reflect the Confucian ethic of frugality, which can be interpreted as an Asian incarnation of the capitalist spirit. Similarly, our work suggests that differences in the spirit of capitalism may explain systematic variations in consumption growth rates and precautionary savings behavior across countries.

\section{LITERATURE CITED}

Bakshi, Gurdip S., and Zhiwu Chen. (1996) "The Spirit of Capitalism and Stock-Market Prices." American Economic Review, 86, 133-57.

Baxter, Marianne, and Urban Jermann. (1999) "Household Production and the Excess Sensitivity of Consumption to Current Income." American Economic Review, 89, 902-20.

Blanchard, Olivier, and N. Gregory Mankiw. (1988) "Consumption: Beyond Certainty Equivalence.” American Economic Association Papers and Proceedings, 173-77.

Caballero, Ricardo J. (1990) "Consumption Puzzles and Precautionary Savings." Journal of Monetary Economics, 25, 113-36.

Campbell, John Y. (1994) "Inspecting the Mechanism: An Analytical Approach to the Stochastic Growth Model." Journal of Monetary Economics, 33, 463-506.

Campbell, John Y., and Angus Deaton. (1989) "Why Is Consumption So Smooth?" Review of Economic Studies, 56, 205-51.

Campbell, John Y., and N. Gregory Mankiw. (1989) "Consumption, Income, and Interest Rates: Reinterpreting the Time Series Evidence.” In NBER Macroeconomics Annual 1989, pp. 185-216. Cambridge, MA: MIT Press.

Carroll, Christopher. (1992) "The Buffer Stock Theory of Saving: Some Macroeconomic Evidence." Brookings Papers on Economic Activity, 2, 61-156.

Carroll, Christopher. (2000) "Why Do the Rich Save So Much?” In Does Atlas Shrug? The Economic Consequences of Taxing the Rich, edited by Joel B. Slemrod. Cambridge, MA: Harvard University Press.

Carroll, Christopher. (2001) "A Theory of the Consumption Function, with and without Liquidity Constraints." Journal of Economic Literature, 15, 23-46.

Deaton, Angus. (1992) Understanding Consumption. Oxford, UK: Oxford University Press.

Flavin, Marjorie. (1981) "The Adjustment of Consumption to Changing Expectations about Future Income." Journal of Political Economy, 89, 974-1009.

Gong, Liutang, and Heng-fu Zou. (2001) "Money, Social Status, and Capital Accumulation in a Cash-in-Advance Model.” Journal of Money Credit and Banking, 33, 284-93.

Gong, Liutang, and Heng-fu Zou. (2002) "Direct Preferences for Wealth, the Risk Premium Puzzle, Growth, and Policy Effectiveness." Journal of Economic Dynamics and Control, 26, 271-302.

Gourinchas, Pierre-Olivier, and Jonathan Parker. (2002) "Consumption over the Life Cycle." Econometrica, 70, 47-89. 
Grossman, Sanford J., and Robert J. Shiller. (1982) "Consumption Correlatedness and Risk Measurement in Economies with Non-Traded Assets and Heterogeneous Information.” Journal of Financial Economics, 10, 195-210.

Hall, Robert E. (1978) "Stochastic Implications of the Lifecycle-Permanent Income Hypothesis: Theory and Evidence.” Journal of Political Economy, 86, 971-87.

Hall, Robert E. (1988) “Intertemporal Substitution in Consumption.” Journal of Political Economy, 96, 339-57.

Hansen, Lars P., and Kenneth J. Singleton. (1983) "Stochastic Consumption, Risk Aversion, and the Temporal Behavior of Asset Returns." Journal of Political Economy, 91, 249-65.

Lettau, Martin, and Sydney Ludvigson. (2001) "Consumption, Aggregate Wealth and Expected Stock Returns" Journal of Finance, 41, 815-49.

Luo, Yulei, and Eric Young. (Forthcoming) "The Wealth Distribution and the Demand for Status." Macroeconomic Dynamics.

Merton, Robert. (1971) "Optimal Consumption and Portfolio Policies in a Continuous-Time Model." Journal of Economic Theory 3, 373-413.

Smith, William T. (1999) "Risk, the Spirit of Capitalism, and Long-Term Growth" Journal of Macroeconomics, 21, 241-62.

Smith, William T. (2001) "How Does the Spirit of Capitalism Affect Stock-Market Prices?" Review of Financial Studies, 14, 1215-32.

Wang, Neng. (2006) “Generalizing the Permanent-Income Hypothesis: Revisiting Friedman's Conjecture on Consumption.” Journal of Monetary Economics, 53, 737-52.

Weber, Max. (1948) The Protestant Ethic and the Spirit of Capitalism, Trans. by Talcott Parsons, London: George Allen \& Unwin.

Zou, Heng-fu. (1994) “The Spirit of Capitalism and Long-Run Growth.” European Journal of Political Economy, 10, 279-93.

Zou, Heng-fu. (1995) “The Spirit of Capitalism and Savings Behavior.” Journal of Economic Behavior and Organization, 28, 131-43. 